\title{
The antiallodynic action of pregabalin may depend on the suppression of spinal neuronal hyperexcitability in rats with spared nerve injury
}

\author{
Lei Ding $M D^{1 *}$, Jie Cai $M S^{2 *}$, Xiang-Yang Guo MD ${ }^{1}$, Xiu-Li Meng MD ${ }^{1}$, Guo-Gang Xing PhD ${ }^{2}$
}

\begin{abstract}
L Ding, J Cai, X-Y Guo, X-L Meng, G-G Xing. The antiallodynic action of pregabalin may depend on the suppression of spinal neuronal hyperexcitability in rats with spared nerve injury. Pain Res Manag 2014;19(4):205-211.
\end{abstract}

BACKGROUND: Pregabalin (PGB) is a novel antiepileptic drug and is also used as a first-line medication for the treatment of neuropathic pain. However, the mechanisms of its analgesic effects remain largely unknown.

OBJECTIVES: To elucidate the mechanisms underlying the antiallodynic action of PGB in rats with neuropathic pain

METHODS: In a rat model of neuropathic pain induced by spared nerve injury, mechanical allodynia, as a behavioural sign of neuropathic pain, was assessed by measuring 50\% paw withdrawal threshold with von Frey filaments. Activities of dorsal horn wide dynamic range (WDR) neurons were examined by extracellular electrophysiological recording in vivo. RESULTS: Spinal administration of PGB exerted a significant antiallodynic effect and a prominent inhibitory effect on the hypersensitivity of dorsal horn WDR neurons in rats with spared nerve injury.

CONCLUSION: The antiallodynic action of PGB is likely dependent on the suppression of WDR neuron hyperexcitability in rats with neuropathic pain.

Key Words: Electrophysiology; Neuropathic pain; Pregabalin; Spinal dorsal horn; WDR neurons

\section{L'action antiallodynique de la prégabaline peut dépendre de la suppression de l'hyperexcitabilité des neurones spinaux chez des rats ayant une lésion avec épargne nerveuse}

HISTORIQUE : La prégabaline (PGB) est un nouvel antiépileptique, qui est également utilisé comme médicament de première ligne de la douleur neuropathique. Cependant, on ne sait pas grand-chose des mécanismes de ses effets analgésiques.

OBJECTIFS : Déterminer les mécanismes sous-tendant l'action antiallodynique de la PGB chez des rats ayant une douleur neuropathique.

MÉTHODOLOGIE : Chez un modèle de rat ayant une douleur neuropathique induite par une lésion avec épargne nerveuse, les chercheurs ont évalué l'allodynie mécanique comme signe comportemental de douleur neuropathique en mesurant le seuil de retrait de la patte à $50 \%$ à l'application des filaments de von Frey. Ils ont examiné les activités des neurones de la corne dorsale à la plage dynamique étendue (WDR) au moyen d'un enregistrement électrophysiologique extracellulaire in vivo. RÉSULTATS : L'administration spinale de PGB exerçait un effet antiallodynamique important et un effet inhibiteur significatif sur l'hypersensibilité des neurones de la corne dorsale à WDR de rats ayant une lésion avec épargne nerveuse.

CONCLUSION : L'action antiallodynique de la PGB dépend probablement de la suppression de l'hyperexcitabilité des neurones à WDR chez des rats neuropathiques.
Teuropathic pain, caused by a lesion or disease affecting the som1 atosensory system (1), is a common problem and may affect approximately $8 \%$ of the general population (2). Persistent allodynia, hyperalgesia and spontaneous pain are common characteristics of neuropathic pain, which can impair the quality of life of patients $(3,4)$. The management of neuropathic pain is challenging. Conventional analgesics, such as nonsteroidal anti-inflammatory drugs and opioids, have limited efficacy and serious side effects in the treatment of this condition (5). Recently, the anticonvulsant pregabalin (PGB) and its close analogue gabapentin (GBP) have emerged as alternative treatments for neuropathic pain $(3,6,7)$. With a superior pharmacokinetic profile to its analogue GBP (8), PGB has quickly become a first-line medication for the treatment of neuropathic pain (9). However, the mechanism of its analgesic action remains largely unknown.

PGB (Lyrica; Pfizer, USA), also known as S-(+)-3-(aminomethyl)5-methylhexanoic acid or $S(+)$-3-isobutyl-gamma aminobutyric acid (isobutylgaba), is a potent ligand for the alpha-2-delta $(\alpha 2 \delta)$ subunit of the voltage-gated calcium channels (10-12). Its potent binding at this site attenuates calcium influx to presynaptic nerve endings (13), reducing the release of several neurotransmitters involved in nociceptive transmission, such as glutamate (14-16), norepinephrine (17), substance P and calcitonin gene-related peptide (18), thereby attenuating spinal neuronal hyperexcitability (19). Accordingly, PGB exhibits potent analgesic activity in a range of animal models $(7,14,20-24)$, as well as in preclinical and clinical observations (25. $31)$. Although the $\alpha 2 \delta$ subunit of the presynaptic calcium channels may be the primary target for mediating the analgesic actions of PGB (11-13,32), additional mechanisms underlying the analgesic actions of PGB may also be involved. Recent animal studies suggest that PGB may impair the development or maintenance of spinal central sensitization underlying the hyperalgesic state $(19,33)$. PGB suppresses spinal neuronal hyperexcitability and visceral hypersensitivity in the absence of peripheral pathophysiology in a rat model of opioid-induced hyperalgesia (19). Based on this background, we hypothesized that the antiallodynic action of PGB depends on the suppression of spinal neuronal hyperexcitability in rats with

\footnotetext{
*These authors contributed equally to this work

${ }^{1}$ Department of Anesthesiology, Peking University Third Hospital; ${ }^{2}$ Neuroscience Research Institute and Department of Neurobiology, Peking University; Key Laboratory for Neuroscience of the Ministry of Education and the Ministry of Public Health, Beijing, People's Republic of China

Correspondence: Dr Guo-Gang Xing, Neuroscience Research Institute, Peking University, 38 Xue-Yuan Road, Beijing 100191, People's Republic of China. Telephone 8610-82801067, fax 8610-82801067, e-mail ggxing@bjmu.edu.cn; Dr Xiu-Li Meng, Department of Anesthesiology, Peking University Third Hospital, Beijing 100191, People’s Republic of China. E-mail meng_xiuli@163.com
} 
neuropathic pain. The antiallodynic effects of PGB and the effects of PGB on hypersensitivity of dorsal horn wide dynamic range (WDR) neurons in the spinal cord were, therefore, examined in a rat model of neuropathic pain induced by spared nerve injury (SNI). We demonstrate that spinal administration of PGB significantly alleviates the mechanical allodynia and inhibits the hypersensitivity of dorsal horn WDR neurons in SNI rats.

\begin{abstract}
Animals
Male Sprague-Dawley rats, weighing $180 \mathrm{~g}$ to $200 \mathrm{~g}$ at the beginning of the experiment, were provided by the Department of Experimental Animal Sciences, Peking University Health Science Center (Beijing, China). The rats were housed in separated cages with free access to food and water. The room temperature was maintained at $24 \pm 1^{\circ} \mathrm{C}$ under a natural light-dark cycle. All animal experimental procedures were conducted in accordance with the guidelines of the International Association for the Study of Pain (34) and were approved by the Animal Care and Use Committee of Peking University.
\end{abstract}

\section{METHODS}

\section{SNI}

Under general anesthesia with chloral hydrate $(0.3 \mathrm{~g} / \mathrm{kg}$ administered intraperitoneally [ip]), the SNI procedure comprised an axotomy and ligation of the left tibial and common peroneal nerves, leaving the sural nerve intact. The common peroneal and the tibial nerves were tightly ligated with 4-0 silk sutures and sectioned distal to the ligation, removing $2 \mathrm{~mm}$ to $4 \mathrm{~mm}$ of the distal nerve stump. Considerable care was taken to avoid contact with or stretching of the intact sural nerve, as previously described by Decosterd and Woolf (35). In control animals, sham surgery involved exposure of the sciatic nerve and its branches without generating any lesions. Ten days after surgery, behavioural testing, immunohistochemical staining or electrophysiological recording were performed. Any rats exhibiting motor deficiency or lack of tactile allodynia after SNI surgery were excluded from the present study.

\section{Behavioural studies}

Implantation of intrathecal catheter: Under chloral hydrate $(0.3 \mathrm{~g} / \mathrm{kg}$ ip) anesthesia, implantation of intrathecal cannula was performed following the method described in the authors' previous studies $(36,37)$. Briefly, a PE-10 polyethylene catheter was implanted between the L5 and L6 vertebrae to reach the lumber enlargement of the spinal cord. The outer section of the catheter was plugged and fixed to the skin on closure of the wound. All surgical procedures were performed under sterile conditions. Rats showing neurological deficits following the catheter implantation were euthanized. Drugs or vehicle were intrathecally injected via the implanted catheter in a $20 \mu \mathrm{L}$ volume of solution followed by $10 \mu \mathrm{L}$ of normal saline (NS) for flushing. Each injection lasted for at least $5 \mathrm{~min}$. After an injection, the needle remained in situ for 2 min before being withdrawn.

Assessment of mechanical allodynia: Mechanical allodynia, as a behavioural sign of neuropathic pain, was assessed by measuring $50 \%$ paw withdrawal threshold (PWT) as described in the authors' previous studies $(38,39)$. The $50 \%$ PWT in response to a series of von Frey filaments (Stoelting, USA) was determined using the up-and-down method (40). Briefly, the rat was placed on a metal mesh floor covered with an inverted clear plastic cage $(18 \mathrm{~cm} \times 8 \mathrm{~cm} \times 8 \mathrm{~cm})$ and allowed a $20 \mathrm{~min}$ period for habituation. Eight von Frey filaments with approximately equal logarithmic incremental $(0.224 \mathrm{~g})$ bending forces were chosen $(0.41 \mathrm{~g}, 0.70 \mathrm{~g}, 1.20 \mathrm{~g}, 2.00 \mathrm{~g}, 3.63 \mathrm{~g}, 5.50 \mathrm{~g}$, $8.50 \mathrm{~g}$ and $15.10 \mathrm{~g}$ ). Each trial began with a von Frey force of $2.00 \mathrm{~g}$ delivered perpendicularly to the plantar surface of the left hind paw for approximately $2 \mathrm{~s}$ to $3 \mathrm{~s}$. An abrupt withdrawal of the foot during stimulation or immediately after the removal of the filament was recorded as a positive response. Whenever there was a positive or negative response, the subsequent weaker or stronger filament was applied, respectively. This procedure was continued for six stimuli after the first change in response had been observed. The 50\% PWT was calculated using the following formula:

$$
50 \% \text { PWT }=10^{\left(X_{f}+k \delta\right)}
$$

where $X_{f}$ is the value of the final von Frey filament used (in log units), $\mathrm{k}$ is a value measured from the pattern of positive/negative responses and $\delta=0.224$, which is the average interval (in log units) between the von Frey filaments (41). If an animal responded to the lowest von Frey filament, a value of $0.25 \mathrm{~g}$ was assigned. If an animal did not respond to the highest von Frey filament, the value was recorded as $15.0 \mathrm{~g}$. In rats, mechanical allodynia is assessed by measuring the 50\% PWT in response to von Frey filaments, and the rat is considered to be allodynic when the $50 \%$ PWT is $<4.0 \mathrm{~g}$ (ie, withdrawal in response to non-noxious tactile stimulus) (36).

The antiallodynic effects of PGB were presented as 50\% PWT in grams or as percentages of the maximum possible effect (MPE) following the formula described by Obata et al (42):

$$
\begin{gathered}
\text { MPE }=(\text { postdrug PWT value }- \text { predrug PWT value }) \\
\times 100 /(15 \text { g cut-off value }- \text { predrug PWT value }) \times 100 \%
\end{gathered}
$$

PGB, at a dose of $100 \mu$ in a $20 \mu \mathrm{L}$ volume of solution, or an equal volume of vehicle (NS) was intrathecally administrated to rats on day 10 after SNI surgery (once per day for three days). The inclined-plate testing was performed before drug injection and on day 3 following drug injection, respectively, to assess the effect of PGB on motor function.

Assessment of locomotor function: Inclined-plate testing was used for the assessment of locomotor function. The rat was placed crosswise to the long axis of an inclined plate. The initial angle of the inclined plate was $50^{\circ}$. The angle was then adjusted in $5^{\circ}$ increments. The maximum angle of the plate on which the rat maintained its body position for $5 \mathrm{~s}$ without falling was determined, according to the method reported by Rivlin and Tator (43).

\section{Electrophysiological studies}

Surgery: Rats were initially anesthetized using urethane $(1.2 \mathrm{~g} / \mathrm{kg}$ to $1.5 \mathrm{~g} / \mathrm{kg}$ ip). The trachea was cannulated to allow mechanical ventilation with room air. A catheter was inserted into the right jugular vein for continuous infusion of Tyrode's solution $(\mathrm{NaCl} 137 \mathrm{mmol} / \mathrm{L}$, $\mathrm{KCl} 2.7 \mathrm{mmol} / \mathrm{L}, \mathrm{CaCl}_{2} 1.4 \mathrm{mmol} / \mathrm{L}, \mathrm{MgCl}_{2} 1.0 \mathrm{mmol} / \mathrm{L}, \mathrm{NaHCO}_{3}$ $6.0 \mathrm{mmol} / \mathrm{L}, \mathrm{NaH}_{2} \mathrm{PO}_{4} 2.1 \mathrm{mmol} / \mathrm{L}, \mathrm{D}$-[+]-glucose $6.5 \mathrm{mmol} / \mathrm{L}$; $\mathrm{pH} 7.4$ ) at a rate of $1.0 \mathrm{~mL} / \mathrm{h}$ to $1.5 \mathrm{~mL} / \mathrm{h}$. The rectal temperature was maintained at $36.5^{\circ} \mathrm{C}$ to $37.5^{\circ} \mathrm{C}$ via a feedback-controlled heating pad placed under the body. A pair of bipolar silver hook electrodes was placed under the sciatic nerve immediately proximal to the trifurcation for electrical stimulation. The vertebral column was rigidly fixed in the frame with two clamps. The lumbar enlargement of the spinal cord was exposed by laminectomy at the vertebrae T13 and L1, and the dura covering lumbosacral spinal segments was carefully removed. A small well was built with $3 \%$ agar on the dorsal spinal cord at the recording segment to allow application of drugs or vehicles $(39,44)$. The exposed spinal tissue was covered with warm $\left(37^{\circ} \mathrm{C}\right)$ saline solution. After surgery, the animal was artificially ventilated with a small animal ventilator and continuous anesthesia was maintained with urethane $(0.10 \mathrm{~g} / \mathrm{kg} / \mathrm{h}$ to $0.15 \mathrm{~g} / \mathrm{kg} / \mathrm{h})$ during the entire experiment. The depth of anesthesia was monitored by examination of pupillary size and reflexes. The physiological condition of the animal was monitored by recording the electrocardiogram (330 beats $/ \mathrm{min}$ to 460 beats $/ \mathrm{min}$ ), end-expiratory $\mathrm{CO}_{2}(3.5 \%$ to $4.5 \%)$ and rectal temperature $\left(36.5^{\circ} \mathrm{C}\right.$ to $\left.37.5^{\circ} \mathrm{C}\right)$, and was maintained within the ranges indicated (39).

Extracellular recording: Single-unit extracellular recordings were made from the lumbar dorsal horn neurons within $1200 \mu \mathrm{m}$ of the dorsal surface of the spinal cord with $2 \mathrm{M} \Omega$ to $5 \mathrm{M} \Omega$ parylene-coated tungsten microelectrodes (Friedrick Haer \& Co, USA) because the WDR neurons are located in the deep dorsal horn, mainly in laminae IV and V of the dorsal horn in the spinal cord. The 
microelectrode was inserted perpendicularly into the dorsal horn from a point approximately midway between the midline and the medial edge of the dorsal root entry zone. During electrode advancement, electrical pulses $(0.5 \mathrm{~Hz}, 0.3 \mathrm{~ms}$ pulse width, $0.4 \mathrm{~mA})$ were applied to the ipsilateral sciatic nerve as search stimuli to identify a neuron with no spontaneous firing. Once a single unit was identified, the receptive field and response characteristics were determined using a range of mechanical stimuli of varying intensities, including brushing or touching the skin with a cotton brush, light pressure with a probe and pinching a fold of skin with toothed forceps. A neuron responding to innocuous tactile stimuli, light pressure and noxious pinch in a graded manner was identified as a WDR neuron and was selected for further investigation (44). The recorded signals were amplified using an alternating current preamplifier, filtered with a passing bandwidth of $500 \mathrm{~Hz}$ to $1000 \mathrm{~Hz}$, displayed on an oscilloscope and fed to a Pentium computer via a CED 1401 interface for offline analysis using the Spike2 software (Cambridge Electronic Design, United Kingdom). Spikes appearing $45 \mathrm{~ms}$ to $300 \mathrm{~ms}$ after stimulus were defined as C-fibre responses (ie, responses in the WDR neurons evoked by C-fibre activation) (44). Single-cell recording was ensured on the basis of amplitude and shape of the action potentials. In the following electrophysiological studies, only one cell was studied in each animal, and each animal received PGB or vehicle only once.

Measurement of drug effects: The electrophysiological experiment was designed to investigate effects of spinal administration of PGB on the activities of WDR neurons in SNI rats. In this experiment, a train of 10 stimuli $(0.5 \mathrm{~Hz}, 0.5 \mathrm{~ms}$ pulse width, with a pulse current of $2 \times$ C-fibre response threshold), which was used as test stimulus, was applied repeatedly to the sciatic nerve at $5 \mathrm{~min}$ intervals, and poststimulus histograms from the responses of WDR neurons were generated using the Spike2 software. After six stable control responses were recorded, PGB (at a dose of $100 \mu \mathrm{g}$ in a $20 \mu \mathrm{L}$ volume of solution) or an equal volume of vehicle was applied topically to the dorsal surface of the spinal cord, and the postdrug responses evoked by the same test stimulus as above were measured at $5 \mathrm{~min}$ intervals for up to $120 \mathrm{~min}$. In the present study, only C-fibre responses of WDR neurons, which are usually related to nociception $(44,45)$, were examined and analyzed. All of the C-fibre responses were expressed as percentages of the mean response value of six predrug consecutive trains of test stimuli.

\section{Chemical preparation and application}

PGB (S-[+]-3-[aminomethyl]-5-methylhexanoic acid) (Pfizer, USA), was dissolved in sterile $0.9 \%$ saline solution at a final concentration of $5 \mu \mathrm{g} / \mu \mathrm{L}$ and administered at $100 \mu \mathrm{g}$ per application in behavioural or electrophysiological studies.

\section{Statistical analysis}

Statistical analyses were performed using GraphPad Prism 5 (GraphPad Software, USA) for Windows (Microsoft Corporation, USA). All data were expressed as mean \pm SEM. A two-tailed Student's $t$ test was used to compare mean values between two groups. One-way ANOVA followed by the Dunnett multiple-comparison test or two-way ANOVA followed by the Bonferroni post hoc test were used for multiple comparison; $\mathrm{P}<0.05$ was considered to be statistically significant. Area under the time-course curve (AUC) during the analysis time was used to assess the sum of the effects of PGB, as previously described $(39,46)$.

\section{RESULTS}

Effects of intrathecal PGB on the mechanical allodynia and the locomotor function in SNI rats

As shown in Figures 1A and 1B, SNI that comprised an axotomy and ligation of the left tibial and common peroneal nerves produced a significant mechanical allodynia in rats, as assessed by $50 \%$ PWT in response to the mechanical stimulation with von Frey filaments. In contrast to naive and sham controls, the ipsilateral PWT in SNI rats decreased significantly from day $7(14.62 \pm 0.1 \mathrm{~g}$ naive, $13.93 \pm 0.3 \mathrm{~g}$ sham, 3.69 \pm 0.2 g SNI; $\mathrm{P}<0.001$, two-way ANOVA, $\mathrm{n}=10$ per group) to day $14(14.31 \pm 0.2 \mathrm{~g}$ naive, $13.90 \pm 0.3 \mathrm{~g}$ sham, $2.34 \pm 0.3 \mathrm{~g} \mathrm{SNI}$; $\mathrm{P}<0.001$, two-way ANOVA, $\mathrm{n}=10$ per group) after SNI surgery (Figure 1A). The AUC of PWT (zero to 14 days of the analysis time) was significantly decreased from $204.90 \pm 1.0$ (naive) and $199.50 \pm 1.9$ (sham) to $85.17 \pm 1.8$ (SNI) $(\mathrm{P}<0.001$, one-way ANOVA, $\mathrm{n}=10$ per group, Figure $1 \mathrm{~B})$.

Based on the rat model of neuropathic pain induced by SNI, the antiallodynic action of PGB in SNI rats with neuropathic pain was first confirmed. The reduction of the 50\% PWT in SNI rats was found to be markedly reversed by intrathecal administration of PGB. As shown in Figure 1C, the decreased ipsilateral PWT in SNI rats was prominently restored to $13.47 \pm 0.9 \mathrm{~g}$ on day 1 after intrathecal application of PGB (ie, on day 11 after SNI), in contrast to NS application $(3.30 \pm 0.4 \mathrm{~g})(\mathrm{P}<0.001$, two-way ANOVA, $\mathrm{n}=10$ per group). This reversed effect of PGB on PWT lasted for $>3$ days until experiment termination; eg, on day 3 after intrathecal application of PGB (ie, on day 13 after SNI), the ipsilateral PWT in SNI rats was maintained at $13.84 \pm 0.7 \mathrm{~g}$ in contrast to NS application $(3.02 \pm 0.4 \mathrm{~g})$ $(\mathrm{P}<0.001$, two-way ANOVA, $\mathrm{n}=10$ per group $)$. The AUC of the PWT (10 to 13 days of the analysis time) was significantly different between the PGB $(35.51 \pm 2.0)$ and NS $(14.44 \pm 0.7)$ groups $(\mathrm{P}<0.001$, two-tailed unpaired $t$ test, $n=10$ per group, Figure 1D). Similarly, the MPE of PGB on PWT was significantly increased to $87.98 \pm 6.7 \%$ on day 1 after PGB administration (ie, on day 11 after SNI) compared with that in NS control $(2.37 \pm 2.9 \%)(P<0.001$, two-way ANOVA, $\mathrm{n}=10$ per group). On day 3 after $\mathrm{PGB}$ administration (ie, on day 13 after SNI), the MPE of PGB on PWT was still maintained at $90.79 \pm 4.8 \%$ compared with that in the NS control group $(3.88 \pm 1.6 \%) \quad(\mathrm{P}<0.001$, two-way ANOVA, $\mathrm{n}=10$ per group; Figure 1E). To exclude the possibility that the antiallodynic action of PGB was due to the impairment of rat motor function, the effect of $\mathrm{PGB}$ on rat locomotor function was examined using the inclinedplate test. As shown in Figure 1F, no obvious motor dysfunction was observed after spinal administration of PGB in rats with neuropathic pain $\left(69.20 \pm 0.6^{\circ}\right.$ versus $69.13 \pm 0.5^{\circ}$, pre-PGB versus post-PGB, $\mathrm{P}>0.05$, two-tailed unpaired $t$ test, $\mathrm{n}=10$ per group). Collectively, these results suggest that spinal administration of PGB has a significant antiallodynic effect in rats with neuropathic pain.

\section{Effects of spinal administration of PGB on C-fibre responses of dorsal horn WDR neurons in SNI rats}

To further determine whether the antiallodynic action of PGB was dependent on the suppression of spinal neuronal hyperexcitability in rats with neuropathic pain, the C-fibre responses of dorsal horn WDR neurons that are usually related to nociception $(44,45)$ in SNI rats were first examined. The C-fibre responses of WDR neurons increased significantly in SNI rats compared with those in sham rats (Figure 2). As shown in Figure 2C, the total spike count of the electrically evoked C-fibre responses in 10 stimuli was markedly increased in SNI rats in contrast to sham rats $(\mathrm{P}<0.001$, two-way ANOVA, $n=9$ per group). Similarly, the AUC ( $0 \mathrm{~min}$ to $25 \mathrm{~min}$ ) of the $\mathrm{C}$-fibre response was also increased significantly in SNI rats $(4525 \pm 626.1)$ compared with that in sham rats $(1412 \pm 168.9)(\mathrm{P}<0.001$, SNI versus sham, two-tailed unpaired $t$ test, $n=9$ per group, Figure 2D). Two representative examples illustrating the C-fibre responses of dorsal horn WDR neurons in SNI and sham rats are shown in Figure 2A and 2B. These results suggest that SNI produces hypersensitivity of dorsal horn WDR neurons that is highly related to the pathogenesis of neuropathic pain.

Next, the effects of spinal administration of PGB on the C-fibre responses of dorsal horn WDR neurons was examined in SNI rats. As shown in Figure 3, PGB (at $100 \mu \mathrm{g}$ ) had a marked inhibitory effect on the hypersensitivity of dorsal horn WDR neurons in SNI rats. The inhibitory effect of PGB on C-fibre responses of WDR neurons began 


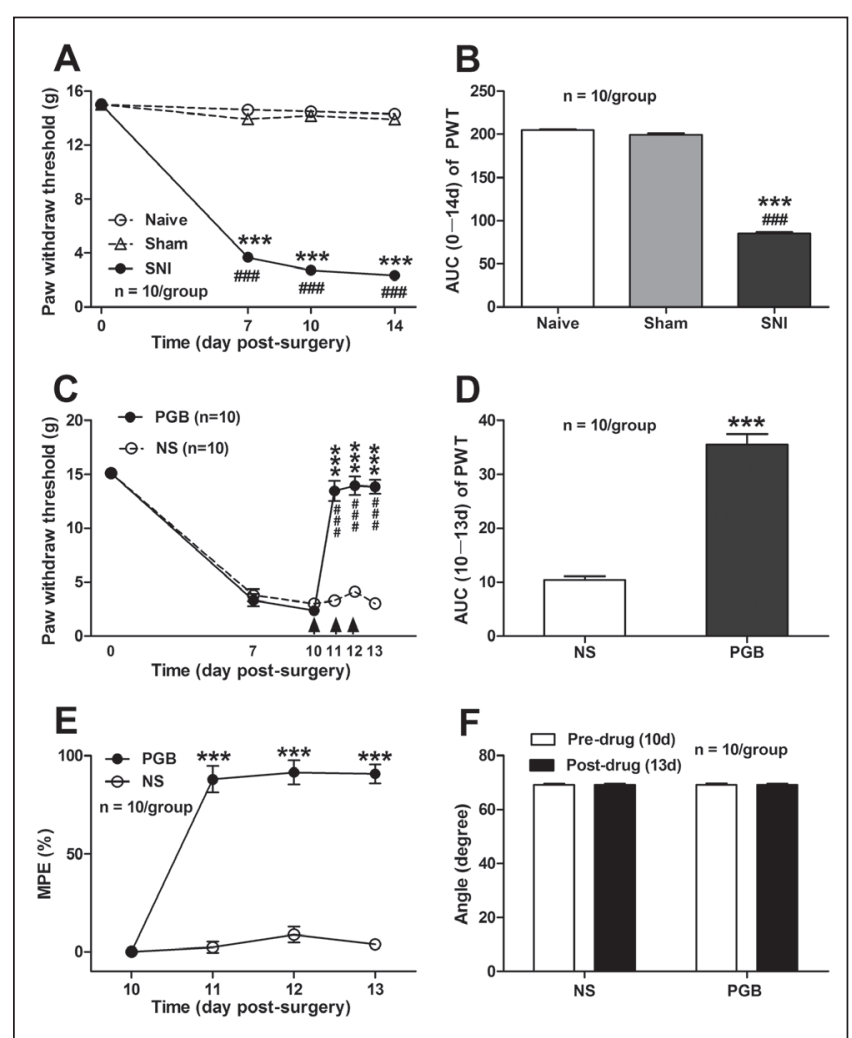

Figure 1) Effects of intrathecal administration of pregabalin (PGB) on mechanical allodynia and locomotor function in a rat model of neuropathic pain induced by spared nerve injury (SNI). A and B Effects of SNI on the mechanical allodynia, as measured by 50\% paw withdrawal threshold (PWT) (A) and area under the time-course curve (AUC) of PWT (B). Note that SNI produced a significant decrease in both 50\% PWT and AUC of the 50\% PWT, in contrast to naive and sham controls. $* * * P<0.001$, \#\#\# $P<0.001$ compared with naive and sham, respectively; one-way ANOVA followed by the Dunnett multiple comparison test or two-way ANOVA followed by Bonferroni post hoc test; $n=10$ per group. C to E Effects of intrathecal administration of PGB on 50\% PWT (C) and the AUC of PWT (D) as well as on the maximum possible effect (MPE) (E) in rats with neuropathic pain. PGB was administered intrathecally on day (d) 10 postsurgery at $100 \mu \mathrm{g} /$ day, once per day for three days. The arrows indicate the injection of PGB or normal saline (NS) on day 10, day 11 and day 12 postsurgery. Note that PGB had a significant reversal effect on the decreased 50\% PWT in SNI rats, in contrast to NS and control (C). ${ }_{* * *} P<0.001,{ }^{\# \# P} P<0.001$, compared with NS and predrug, respectively; two-way ANOVA followed by Bonferroni post hoc test; $n=10$ per group. Similarly, the AUC (10 to 13 day) of PGB on 50\% PWT (D) and the MPE of PGB (E) was markedly increased, in contrast to NS control. ***P<0.001 compared with NS; one-way ANOVA followed by the Dunnett multiple comparison test or two-way ANOVA followed by Bonferroni post hoc test; $n=10$ per group. F Effects of PGB on the locomotor function of rats, measured by the angle of the inclined plate at which the rat begin to fall. Note that spinal administration of PGB had no significant impairment on the locomotor function of rats $(P>0.05$, two-tailed unpaired $\mathrm{t}$ test, predrug versus postdrug; $n=10$ per group)

at $20 \mathrm{~min}$ post-PGB $(70.71 \pm 7.4 \%$ of baseline $)$, peaked at $65 \mathrm{~min}$ $(49.47 \pm 8.8 \%$ of baseline) and lasted $>120 \mathrm{~min}(59.43 \pm 11.6 \%$ of baseline) until experiment termination. Conversely, spinal administration of NS had no significant effect on the C-fibre responses of WDR neurons in SNI rats $(\mathrm{P}<0.05$ to 0.001 , two-way ANOVA, $n=9$ per group, Figure $3 \mathrm{C}$ ). The AUC of the $\mathrm{C}$-fibre responses ( $-25 \mathrm{~min}$ to $120 \mathrm{~min}$ of the analysis time) was also decreased significantly in
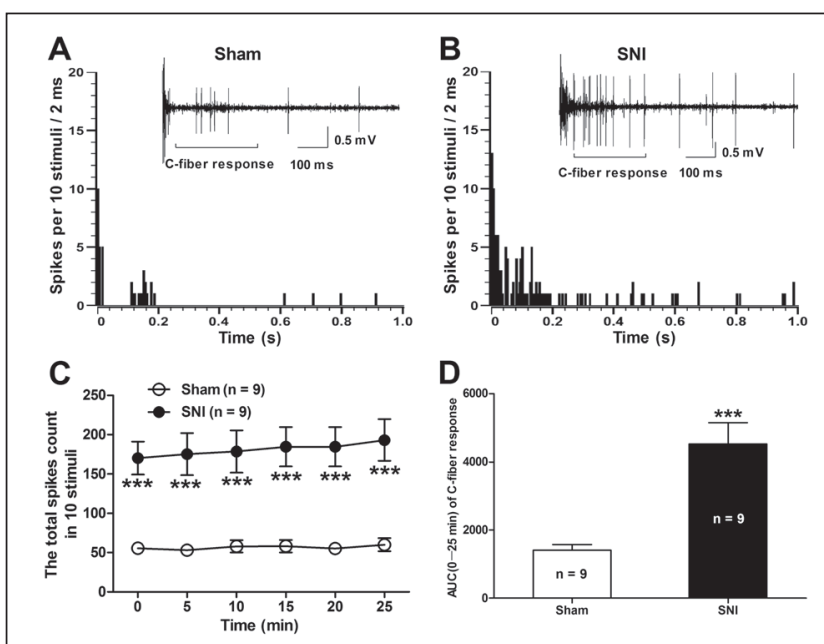

Figure 2) Alterations of the C-fibre responses of dorsal horn wide dynamic range (WDR) neurons in spared nerve injury (SNI) rats. A and $\mathbf{B}$ Panels illustrate the poststimulus histogram of the electrically evoked neuronal responses in a dorsal horn WDR neuron in SNI and sham rats, respectively. The insets show the original recordings of the first electrically evoked neuronal responses. $\mathrm{C}$ The total spike count of the electrically evoked C-fibre responses in 10 stimuli. $* * * P<0.001$ compared with sham control; twoway ANOVA followed by Bonferroni post hoc test; $n=9$ per group. D The area under the time-course curve (AUC) $(0 \mathrm{~min}$ to $25 \mathrm{~min}$ ) of the $\mathrm{C}$-fibre response. $* * * P<0.001$, SNI versus sham, two-tailed unpaired $\mathrm{t}$ test $; n=9$ per group

the PGB group $(10200 \pm 780.2)$ compared with the NS group $(15670 \pm 570.6)(\mathrm{P}<0.001, \mathrm{PGB}$ versus NS, two-tailed unpaired $t$ test, $\mathrm{n}=9$ per group, Figure 3D). Two representative examples illustrating the C-fibre responses of dorsal horn WDR neurons before and after $\mathrm{PGB}$ or NS administration in SNI rats are shown in Figures $3 \mathrm{~A}$ and 3B. These data suggest that the antiallodynic action of PGB is likely dependent on the suppression of spinal neuronal hyperexcitability in rats with neuropathic pain.

\section{DISCUSSION}

In the present study, we found that spinal administration of PGB had a significant antiallodynic effect in a rat model of neuropathic pain induced by SNI, which was associated with a marked inhibitory effect on the hypersensitivity of dorsal horn WDR neurons in SNI rats. These data indicate a novel mechanism underlying the antiallodynic action of PGB that is likely dependent on the suppression of WDR neuron hyperexcitability in neuropathic rats.

Consistent with previous reports that PGB had a potent analgesic activity in rodent models of neuropathic pain $(7,14,23)$, the present study provides evidence showing that intrathecal administration of PGB has a significant reversal effect on the reduction of ipsilateral PWT in response to von Frey filaments in SNI rats, confirming the antiallodynic effect of PGB on neuropathic pain. In the present study, PGB was intrathecally administrated on day 10 postsurgery when stable mechanical allodynia (represented as the reduction of PWT) emerged; therefore, the reversal effect of PGB on the SNI-induced reduction of PWT may be considered to represent the antiallodynic action of PGB on neuropathic pain. Together with the data obtained from the inclined-plate test, which showed that intrathecal injection of PGB had no significant impairment to the locomotor function in SNI rats, we suggest that PGB exerts its antiallodynic action in neuropathic rats without causing motor dysfunction.

PGB is a lipophilic analogue of $\gamma$-aminobutyric acid (GABA), but it neither acts similar to GABA nor binds to GABA receptors $(47,48)$. The $\alpha 2 \delta$ subunit of the plasma membrane voltage-gated calcium channel is regarded as a major site of PGB action $(10-12,49,50)$. 
Its potent binding at this site reduces calcium influx to presynaptic nerve endings (13), which reduces the release of several neurotransmitters involved in nociceptive transmission and will attenuate spinal neuronal hyperexcitability (19). To determine whether the antiallodynic action of PGB was dependent on the suppression of spinal neuronal hyperexcitability in rats with neuropathic pain, we first examined the C-fibre responses of dorsal horn WDR neurons in SNI rats. In the present study, we focused on WDR neurons, particularly C-fibre responses of WDR neurons, because they are polymodal neurons that receive multisynaptic input from A-beta, A-delta and C-fibre primary afferent nociceptors and respond to A-delta and C-fibre-mediated noxious thermal and mechanical stimuli, which are usually related to nociception $(44,45)$. We found that the C-fibre responses of WDR neurons increased significantly in SNI rats, in contrast to sham rats, implying that SNI produces hypersensitivity of dorsal horn WDR neurons that is highly related to the pathogenesis of neuropathic pain $(51-53)$. With regard to the action of PGB, we found that spinal administration of PGB had a marked inhibitory effect on the hypersensitivity of dorsal horn WDR neurons in SNI rats, suggesting that the antiallodynic action of PGB is likely dependent on the suppression of spinal neuronal hyperexcitability in rats with neuropathic pain. Supporting this notion, Wallin et al (33) found that PGB or GBP not only potentiated the antiallodynic effects of spinal cord stimulation (SCS) in rats that do not respond to SCS, but also enhanced the SCS-induced suppression of the hyperexcitability of dorsal horn WDR neurons in neuropathic rats. In morphine-treated rats, Bannister et al (19) showed that PGB attenuated the opioid-induced visceral hypersensitivity and reduced the hyperexcitability of WDR neurons to noxious mechanical and thermal stimuli. In rats with bee venom-induced inflammation, You et al (54) demonstrated that PGB selectively inhibited C-fibremediated, but not A $\delta$-fibre-mediated, spinal nociceptive-specific neuronal late responses including central neuronal plastic changes, ie, wind-up and after-discharges. In addition, in a rat model of craniofacial neuropathic pain, Cao et al (20) reported that PGB effectively attenuated the mechanical hypersensitivity and nociceptive neuronal hyperexcitability recorded in the medullary dorsal horn. Because we did not test responses of WDR neurons and the effects of PGB on responses to natural stimuli in the present study, we could not exclude the possibility that the mechanical allodynia is mediated by increased activity of WDR neurons evoked by low-threshold (A-beta) mechanoreceptors rather than C-fibre nociceptors.

Substantial evidence has shown that the spinal neuronal hyperexcitability contributes to the central sensitization and the pain hypersensitivity in neuropathic rats $(51,52,55-58)$; therefore, inhibition of the hyperexcitability of dorsal horn WDR neurons may account for the antiallodynic action of PGB for the treatment of neuropathic pain in rats. Indeed, emerging evidence suggests that PGB may impair the development or maintenance of spinal central sensitization underlying the hyperalgesic state $(19,33)$, and suppress spinal neuronal hyperexcitability and visceral hypersensitivity in a rat model of opioidinduced hyperalgesia (19).

\section{CONCLUSION}

The present study demonstrated that PGB significantly alleviates the mechanical allodynia and inhibits the hypersensitivity of dorsal horn WDR neurons in SNI rats. These data suggest that the antiallodynic

\section{REFERENCES}

1. Jensen TS, Baron R, Haanpaa M, et al. A new definition of neuropathic pain. Pain 2011;152:2204-5.

2. Torrance N, Smith BH, Bennett MI, Lee AJ. The epidemiology of chronic pain of predominantly neuropathic origin. Results from a general population survey. J Pain 2006;7:281-9.

3. Vranken JH. Elucidation of pathophysiology and treatment of neuropathic pain. Cent Nerv Syst Agents Med Chem 2012;12:304-14

4. Smith BH, Torrance N. Epidemiology of neuropathic pain and its impact on quality of life. Curr Pain Headache Rep 2012;16:191-8.

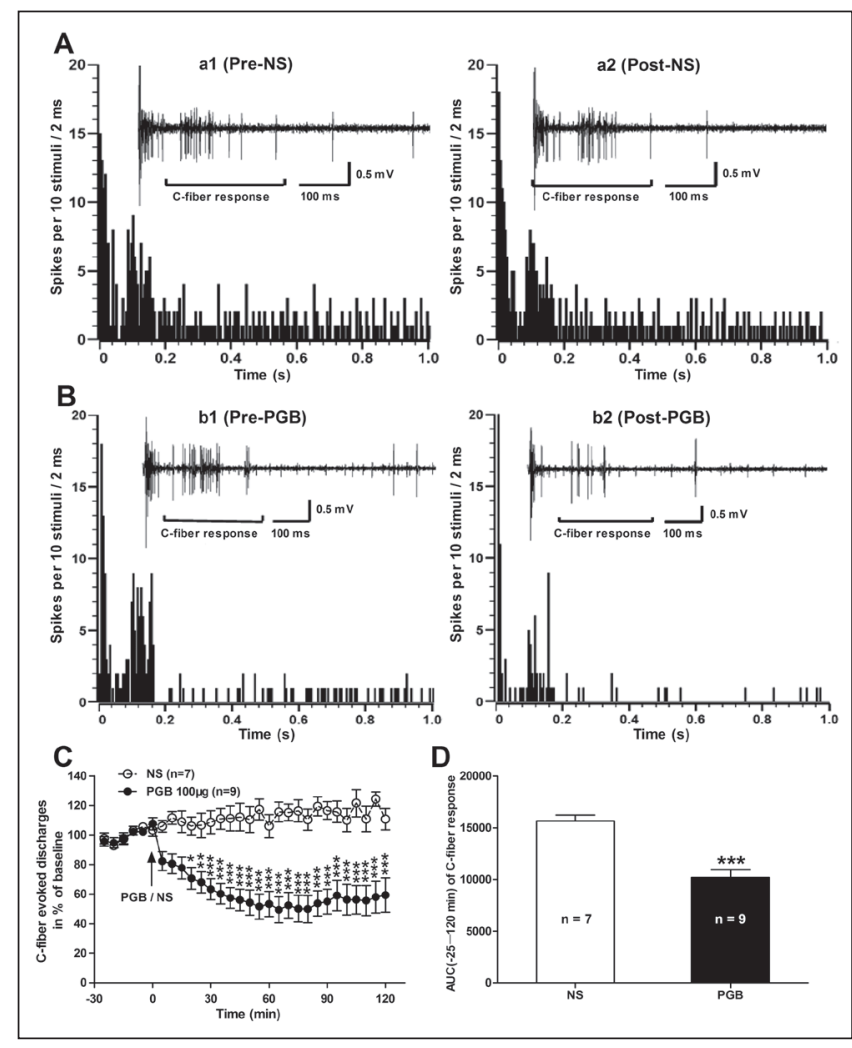

Figure 3) Effects of spinal administration of pregabalin (PGB) on the $\mathrm{C}$-fibre responses of dorsal horn wide dynamic range (WDR) neurons in spared nerve injury (SNI) rats. A and B Panels illustrate the poststimulus histogram of the electrically evoked neuronal responses in a dorsal horn WDR neuron before (a1, normal saline [NS]; b1, PGB) and after (a2, NS; b2, PGB) drug application. The insets show the original recordings of the first electrically evoked neuronal responses corresponding to each time point, respectively. C Analysis of the C-fibre-evoked discharges before and after drug (PGB or NS) application in SNI rats. Note that spinal administration of PGB (at $100 \mu \mathrm{g}$ ) had a significant inhibitory effect on the C-fibreevoked responses, in contrast to the NS control. ${ }^{*} P<0.05 ; * * P<0.01$; $* * * P<0.001$, compared with NS control; two-way ANOVA followed by Bonferroni post hoc test, $n=7$ to 9 per group). D The area under the timecourse curve (AUC) (-25 min to $120 \mathrm{~min}$ ) of the C-fibre response. $* * * P<0.001, P G B$ versus NS; two-tailed unpaired $t$ test, $n=7$ to 9 per group

action of PGB is likely dependent on the suppression of WDR neuron hyperexcitability in neuropathic rats.

ACKNOWLEDGEMENTS: The present work was supported by grants from the National Natural Science Foundation of China (81371237, 31171063, and 61027001), and the '973' Program of the Ministry of Science and Technology of China (2013CB531905).

5. Hurley RW, Adams MC, Benzon HT. Neuropathic pain: Treatment guidelines and updates. Curr Opin Anaesthesiol 2013 August 29 (Epub ahead of print).

6. Blommel ML, Blommel AL. Pregabalin: An antiepileptic agent useful for neuropathic pain. Am J Health Syst Pharm 2007;64:1475-82.

7. Salat K, Librowski T, Nawiesniak B, Gluch-Lutwin M. Evaluation of analgesic, antioxidant, cytotoxic and metabolic effects of pregabalin for the use in neuropathic pain. Neurol Res 2013;35:948-58. 
8. Guay DR. Pregabalin in neuropathic pain: A more "pharmaceutically elegant" gabapentin? Am J Geriatr Pharmacother 2005;3:274-87.

9. Brix FN, Hein SS, Staehelin JT. Management of painful neuropathies. Handb Clin Neurol 2013;115:279-90.

10. Bian F, Li Z, Offord J, et al. Calcium channel alpha2-delta type 1 subunit is the major binding protein for pregabalin in neocortex, hippocampus, amygdala, and spinal cord: An ex vivo autoradiographic study in alpha2-delta type 1 genetically modified mice. Brain Res 2006;1075:68-80.

11. Field MJ, Cox PJ, Stott E, et al. Identification of the alpha2-delta-1 subunit of voltage-dependent calcium channels as a molecular target for pain mediating the analgesic actions of pregabalin. Proc Natl Acad Sci U S A 2006;103:17537-42.

12. Taylor CP. Mechanisms of analgesia by gabapentin and pregabalin calcium channel alpha2-delta [Cavalpha2-delta] ligands. Pain 2009;142:13-6.

13. Joshi I, Taylor CP. Pregabalin action at a model synapse: Binding to presynaptic calcium channel alpha2-delta subunit reduces neurotransmission in mice. Eur J Pharmacol 2006;553:82-8.

14. Kumar N, Laferriere A, Yu JS, Leavitt A, Coderre TJ. Evidence that pregabalin reduces neuropathic pain by inhibiting the spinal release of glutamate. J Neurochem 2010;113:552-61.

15. Kumar N, Cherkas PS, Varathan V, et al. Systemic pregabalin attenuates facial hypersensitivity and noxious stimulus-evoked release of glutamate in medullary dorsal horn in a rodent model of trigeminal neuropathic pain. Neurochem Int 2013;62:831-5.

16. Quintero JE, Dooley DJ, Pomerleau F, Huettl P, Gerhardt GA. Amperometric measurement of glutamate release modulation by gabapentin and pregabalin in rat neocortical slices: Role of voltagesensitive Ca2 + alpha2delta-1 subunit. J Pharmacol Exp Ther 2011;338:240-5.

17. Dooley DJ, Donovan CM, Pugsley TA. Stimulus-dependent modulation of $[(3) \mathrm{H}]$ norepinephrine release from rat neocortical slices by gabapentin and pregabalin. J Pharmacol Exp Ther 2000;295:1086-93.

18. Fehrenbacher JC, Taylor CP, Vasko MR. Pregabalin and gabapentin reduce release of substance P and CGRP from rat spinal tissues only after inflammation or activation of protein kinase C.

Pain 2003;105:133-41.

19. Bannister K, Sikandar S, Bauer CS, Dolphin AC, Porreca F, Dickenson AH. Pregabalin suppresses spinal neuronal hyperexcitability and visceral hypersensitivity in the absence of peripheral pathophysiology. Anesthesiology 2011;115:144-52.

20. Cao Y, Wang H, Chiang CY, Dostrovsky JO, Sessle BJ. Pregabalin suppresses nociceptive behavior and central sensitization in a rat trigeminal neuropathic pain model. J Pain 2013;14:193-204.

21. Gustafsson H, Sandin J. Oral pregabalin reverses cold allodynia in two distinct models of peripheral neuropathic pain. Eur J Pharmacol 2009;605:103-8.

22. Han DW, Kweon TD, Lee JS, Lee YW. Antiallodynic effect of pregabalin in rat models of sympathetically maintained and sympathetic independent neuropathic pain. Yonsei Med J 2007;48:41-7.

23. Park HJ, Joo HS, Chang HW, et al. Attenuation of neuropathyinduced allodynia following intraplantar injection of pregabalin. Can J Anaesth 2010;57:664-71.

24. Tanabe M, Takasu K, Takeuchi Y, Ono H. Pain relief by gabapentin and pregabalin via supraspinal mechanisms after peripheral nerve injury. J Neurosci Res 2008;86:3258-64.

25. Baron R, Brunnmuller U, Brasser M, May M, Binder A. Efficacy and safety of pregabalin in patients with diabetic peripheral neuropathy or postherpetic neuralgia: Open-label, non-comparative, flexible-dose study. Eur J Pain 2008;12:850-8.

26. Boyle J, Eriksson ME, Gribble L, et al. Randomized, placebocontrolled comparison of amitriptyline, duloxetine, and pregabalin in patients with chronic diabetic peripheral neuropathic pain: Impact on pain, polysomnographic sleep, daytime functioning, and quality of life. Diabetes Care 2012;35:2451-8.

27. Cardenas DD, Nieshoff EC, Suda K, et al. A randomized trial of pregabalin in patients with neuropathic pain due to spinal cord injury. Neurology 2013;80:533-9.

28. Jenkins TM, Smart TS, Hackman F, Cooke C, Tan KK. Efficient assessment of efficacy in post-traumatic peripheral neuropathic pain patients: Pregabalin in a randomized, placebo-controlled, crossover study. J Pain Res 2012;5:243-50.
29. Saldana MT, Perez C, Navarro A, Masramon X, Rejas J. Pain alleviation and patient-reported health outcomes following switching to pregabalin in individuals with gabapentin-refractory neuropathic pain in routine medical practice. Clin Drug Investig 2012;32:401-12.

30. Stacey BR, Swift JN. Pregabalin for neuropathic pain based on recent clinical trials. Curr Pain Headache Rep 2006;10:179-84

31. Vinik A, Emir B, Cheung R, Whalen E. Relationship between pain relief and improvements in patient function/quality of life in patients with painful diabetic peripheral neuropathy or postherpetic neuralgia treated with pregabalin. Clin Ther 2013;35:612-23.

32. Bauer CS, Rahman W, Tran-van-Minh A, Lujan R, Dickenson AH, Dolphin AC. The anti-allodynic alpha(2)delta ligand pregabalin inhibits the trafficking of the calcium channel alpha(2)delta-1 subunit to presynaptic terminals in vivo. Biochem Soc Trans 2010;38:525-8.

33. Wallin J, Cui JG, Yakhnitsa V, Schechtmann G, Meyerson BA, Linderoth B. Gabapentin and pregabalin suppress tactile allodynia and potentiate spinal cord stimulation in a model of neuropathy. Eur J Pain 2002;6:261-72.

34. Zimmermann M. Ethical guidelines for investigations of experimental pain in conscious animals. Pain 1983;16:109-10.

35. Decosterd I, Woolf CJ. Spared nerve injury: An animal model of persistent peripheral neuropathic pain. Pain 2000;87:149-58.

36. Liu M, Yang H, Fang D, et al. Upregulation of P2X3 receptors by neuronal calcium sensor protein VILIP-1 in dorsal root ganglions contributes to the bone cancer pain in rats. Pain 2013;154:1551-68.

37. Zheng Q, Fang D, Cai J, Wan Y, Han JS, Xing GG. Enhanced excitability of small dorsal root ganglion neurons in rats with bone cancer pain. Mol Pain 2012;8:24.

38. Geng SJ, Liao FF, Dang WH, et al. Contribution of the spinal cord BDNF to the development of neuropathic pain by activation of the NR2B-containing NMDA receptors in rats with spinal nerve ligation. Exp Neurol 2010;222:256-66.

39. Qu XX, Cai J, Li MJ, et al. Role of the spinal cord NR2Bcontaining NMDA receptors in the development of neuropathic pain. Exp Neurol 2009;215:298-307.

40. Chaplan SR, Bach FW, Pogrel JW, Chung JM, Yaksh TL. Quantitative assessment of tactile allodynia in the rat paw. J Neurosci Methods 1994;53:55-63.

41. Dixon WJ. Efficient analysis of experimental observations. Annu Rev Pharmacol Toxicol 1980;20:441-62.

42. Obata H, Saito S, Sasaki M, Ishizaki K, Goto F. Antiallodynic effect of intrathecally administered 5-HT(2) agonists in rats with nerve ligation. Pain 2001;90:173-9.

43. Rivlin AS, Tator CH. Objective clinical assessment of motor function after experimental spinal cord injury in the rat. J Neurosurg 1977;47:577-81.

44. Liu FY, Qu XX, Ding X, et al. Decrease in the descending inhibitory 5 -HT system in rats with spinal nerve ligation. Brain Res 2010;1330:45-60.

45. Lu Y, Perl ER. Selective action of noradrenaline and serotonin on neurones of the spinal superficial dorsal horn in the rat. J Physiol 2007;582:127-36.

46. Zheng Q, Fang D, Liu M, et al. Suppression of KCNQ/M (Kv7) potassium channels in dorsal root ganglion neurons contributes to the development of bone cancer pain in a rat model. Pain 2013;154:434-48.

47. Errante LD, Petroff OA. Acute effects of gabapentin and pregabalin on rat forebrain cellular GABA, glutamate, and glutamine concentrations. Seizure 2003;12:300-6.

48. Cheng JK, Lee SZ, Yang JR, et al. Does gabapentin act as an agonist at native GABA(B) receptors? J Biomed Sci 2004;11:346-55.

49. Fink K, Dooley DJ, Meder WP, et al. Inhibition of neuronal $\mathrm{Ca}(2+)$ influx by gabapentin and pregabalin in the human neocortex. Neuropharmacology 2002;42:229-36.

50. Taylor CP, Angelotti T, Fauman E. Pharmacology and mechanism of action of pregabalin: The calcium channel alpha2-delta (alpha2delta) subunit as a target for antiepileptic drug discovery. Epilepsy Res 2007;73:137-50.

51. Chu KL, Faltynek CR, Jarvis MF, McGaraughty S. Increased WDR spontaneous activity and receptive field size in rats following a neuropathic or inflammatory injury: Implications for mechanical sensitivity. Neurosci Lett 2004;372:123-6. 
52. Sotgiu ML, Biella G. Contribution of central sensitization to the pain-related abnormal activity in neuropathic rats. Somatosens Mot Res 2000;17:32-8.

53. Tabo E, Jinks SL, Eisele JH Jr, Carstens E. Behavioral manifestations of neuropathic pain and mechanical allodynia, and changes in spinal dorsal horn neurons, following L4-L6 dorsal root constriction in rats. Pain 1999;80:503-20.

54. You HJ, Lei J, Arendt-Nielsen L. Selective inhibitory effects of pregabalin on peripheral C but not A-delta fibers mediated nociception in intact and spinalized rats. Neuroscience 2009;164:1845-53.

55. Latremoliere A, Woolf CJ. Central sensitization: A generator of pain hypersensitivity by central neural plasticity. J Pain 2009;10:895-926.
56. Rygh LJ, Kontinen VK, Suzuki R, Dickenson AH. Different increase in $\mathrm{C}$-fibre evoked responses after nociceptive conditioning stimulation in sham-operated and neuropathic rats. Neurosci Lett 2000;288:99-102.

57. Sotgiu ML, Biella G. Differential effects of MK-801, a N-methyl-Daspartate non-competitive antagonist, on the dorsal horn neuron hyperactivity and hyperexcitability in neuropathic rats.

Neurosci Lett 2000;283:153-6.

58. Yakhnitsa V, Linderoth B, Meyerson BA. Spinal cord stimulation attenuates dorsal horn neuronal hyperexcitability in a rat model of mononeuropathy. Pain 1999;79:223-33. 


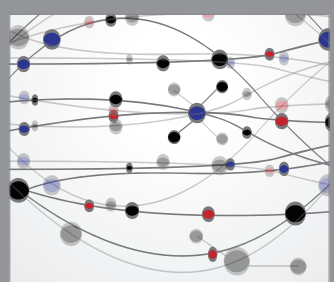

The Scientific World Journal
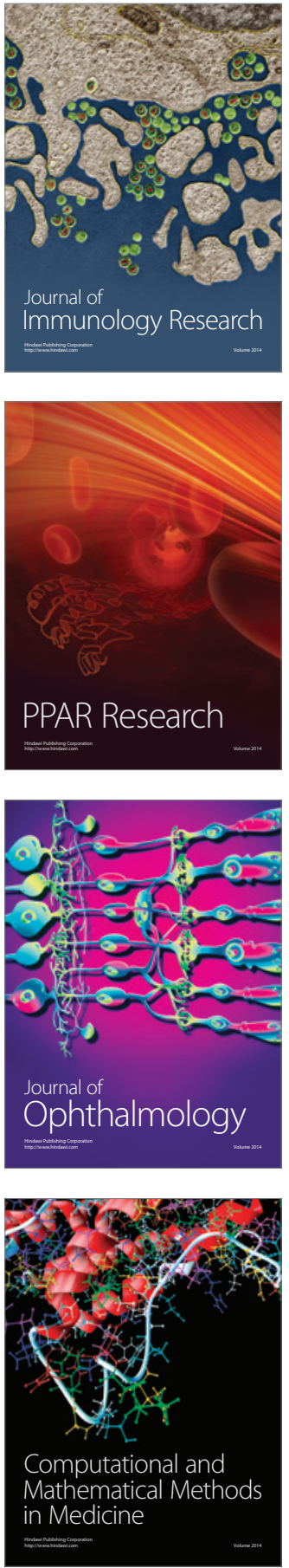

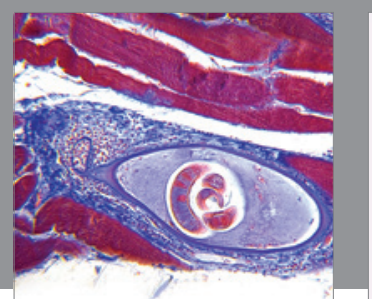

Gastroenterology Research and Practice

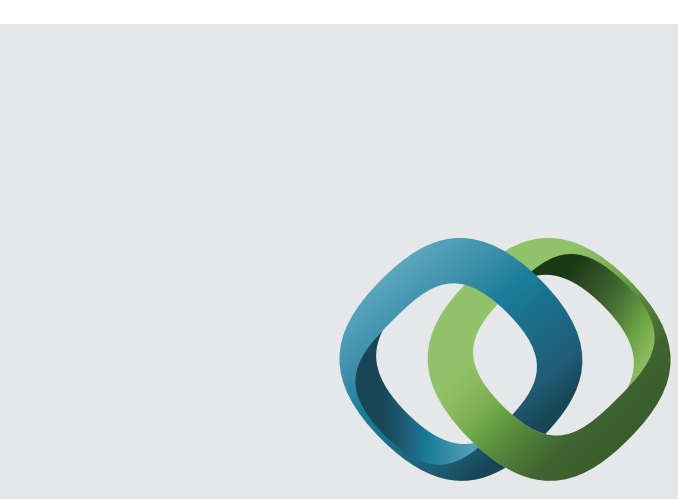

\section{Hindawi}

Submit your manuscripts at

http://www.hindawi.com
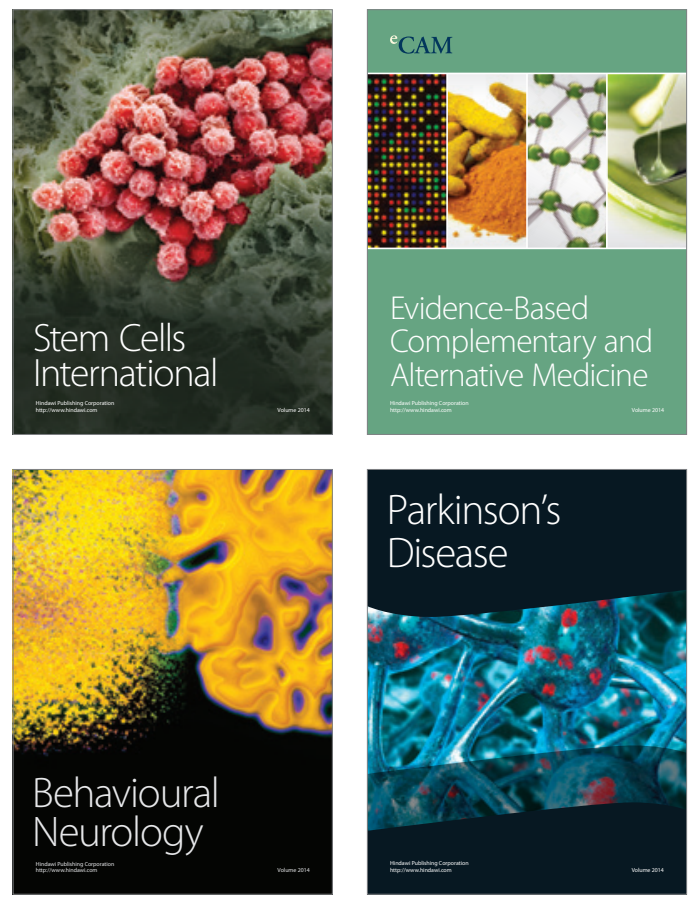
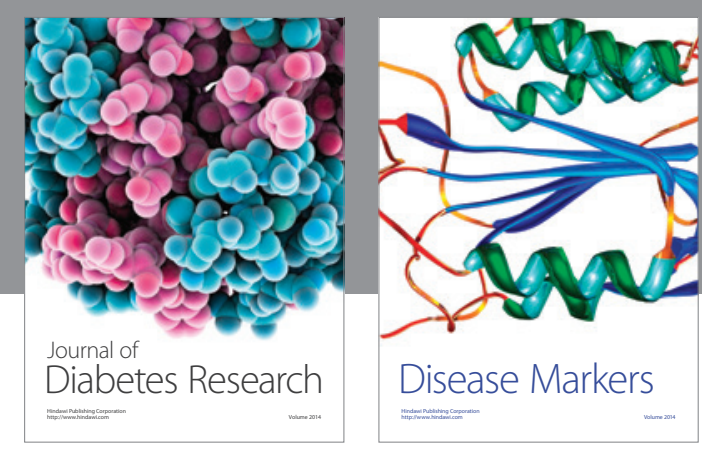

Disease Markers
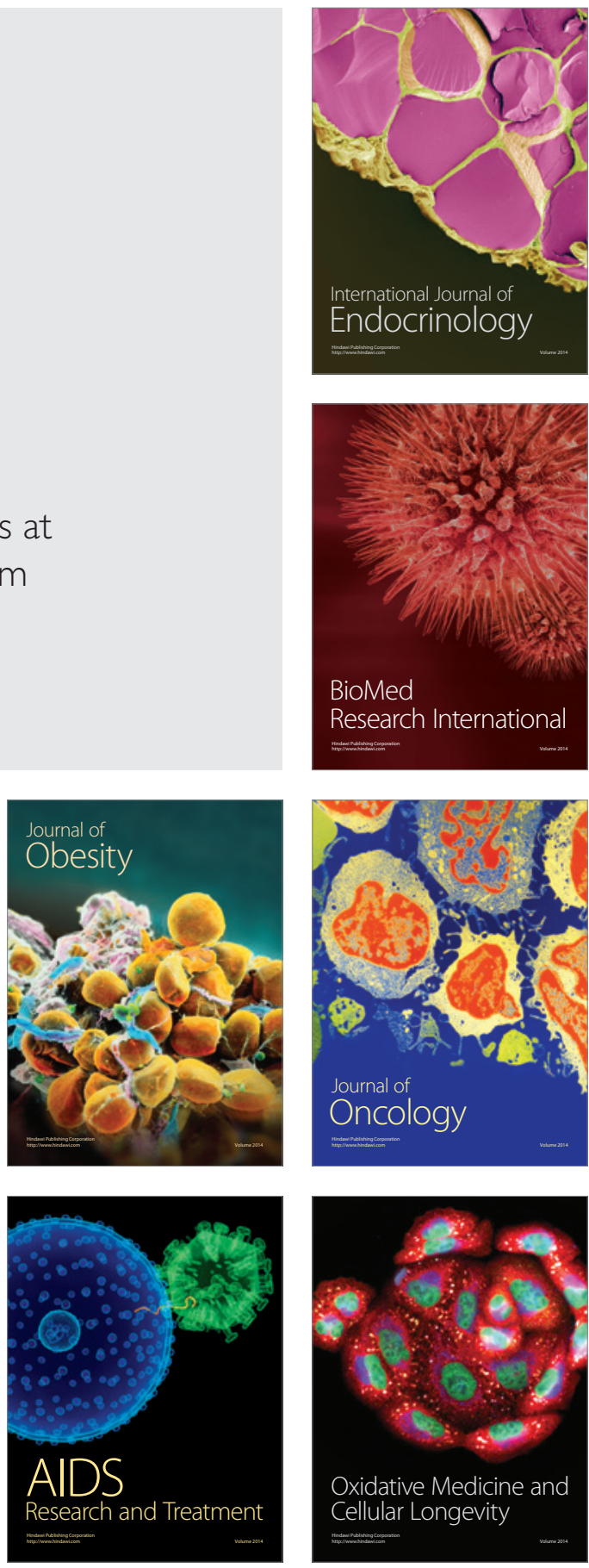